\title{
N

\section{Das fontes orais às fontes visuais: narrativas das ações do Mobral cultural no sertão de Alagoas (1973-1985)}

\author{
From oral sources to visual sources: narratives of the actions of the \\ cultural Mobral in outback the Alagoas (1973-1985)
}

\section{Jailson Costa da Silva}

Professor do Instituto Federal de Alagoas - Campus Piranhas, Maceió, Alagoas, Brasil. jailsonsandes2009@gmail.com - http://orcid.org/0000-0001-5078-3603

Marinaide Lima de Queiroz Freitas

Professora da Universidade Federal de Alagoas, Maceió, Alagoas, Brasil. naide12@hotmail.com - http://orcid.org/0000-0003-3659-4165

Recebido em 22 de fevereiro de 2019

Aprovado em 27 de agosto de 2019

Publicado em 20 de novembro de 2019

\section{RESUMO}

O artigo objetiva apresentar narrativas sobre as ações do Programa Mobral Cultural, implementado pelo Movimento Brasileiro de Alfabetização (Mobral), no município de Santana do Ipanema-AL (1973-1985), com o desígnio de reconstrução da memória em Educação de Jovens e Adultos (EJA). Trata-se de um recorte de uma pesquisa que buscou compreender - a partir de fontes orais e visuais -, como os sujeitos do sertão alagoano experienciaram e ressignificaram as ações culturais desenvolvidas pelo Mobral em um contexto de Ditadura civil-militar. Os depoimentos foram colhidos por meio da abordagem qualitativa da história oral, com base nos postulados teóricos de Alberti (2008), Portelli (2010), Bosi (1994) e Thompson (1992) privilegiando, também, a fotografia como fonte baseado em Cartier-Bresson (1971), Leite (1993) e Mauad (1996). As fontes orais e visuais trouxeram novas reflexões em relação ao lugar - sertão alagoano. Isso nos fez perceber as contribuições e ressignificações que foram possíveis no contexto da investigação, entre elas a apropriação dos artistas locais das ações culturais desenvolvidas em um Movimento marcado pela Ditadura civil-militar.

Palavras-chave: Mobral Cultural; Memória; Narrativas. 


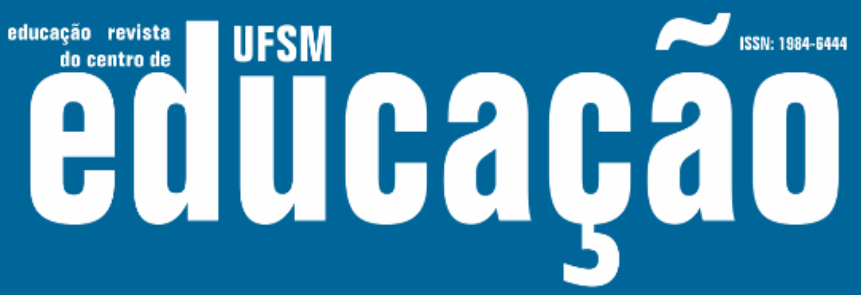

ISSN: 1984-6444 | http://dx.doi.org/10.5902/1984644437025

\section{ABSTRACT}

The article aims to present narratives about the actions of the Mobral Cultural Program, implemented by the Brazilian Movement of Literacy (Mobral), in the municipality of Santana do Ipanema-AL (1973-1985), with the purpose of reconstructing memory in Youth and Adult Education (EJA). It is a cut of a research that sought to understand from oral and visual sources - how the subjects of the Alagoan outback experienced and re-signified the cultural actions developed by Mobral in a context of civil-military dictatorship. The interviews were collected through the qualitative approach of oral history, based on the theoretical postulates of Alberti (2008), Portelli (2010), Bosi (1994) and Thompson (1992), also focusing on photography as a source based on Cartier- Bresson (1971), Leite (1993) and Mauad (1996). The oral and visual sources brought new reflections regarding the place - the Alagoan outback. This made us realize the contributions and resignifications that were possible in the context of the investigation, among them the appropriation of the local artists of the cultural actions developed in a Movement marked by the civil-military Dictatorship.

Keywords: Cultural Mobral; Memory; Narratives.

\section{Considerações iniciais}

Este texto parte de um estudo que tem conexão com o Centro de Referência e Memória da Educação Popular e Educação de Jovens e Adultos (CReMEJA ${ }^{1}$ ), contando com o envolvimento de pesquisadores da Universidade do Estado do Rio de Janeiro (UerJ), que se constituiu como política pública da então Secretaria de Educação Continuada, Alfabetização e Diversidade (Secad/MEC), nos anos 20082010. Tal iniciativa estendeu-se a outras universidades brasileiras em rede de interlocução de pesquisadores a exemplo da Universidade Federal de Alagoas (Ufal).

Apoiada em fontes de diversas naturezas como: entrevista, fotografia e documentos variados, essa pesquisa teve como objetivo compreender: a partir da tessitura das histórias e memórias, como os sujeitos do sertão alagoano experienciaram e ressignificaram as ações culturais desenvolvidas pelo Mobral no contexto de ditadura civil-militar².

Nesse sentido, foi nosso desejo, por meio das narrativas orais e visuais, registrar as atividades do Mobral em Santana do Ipanema $^{3}$, partindo da seguinte problematização: quais foram as contribuições e ressignificações experienciadas 


\section{Autตaดูão}

ISSN: 1984-6444 | http://dx.doi.org/10.5902/1984644437025

pelos sujeitos sertanejos, no campo das ações culturais do Mobral no município de Santana do Ipanema-AL (1973 - 1985)?

Definimos contribuições como elementos que os sertanejos conseguiram absorver a partir da socialização de culturas diferentes com ênfase nas mudanças que ocorreram com os sujeitos que participaram do Programa de atividades culturais do Mobral. Compreendemos como ressignificações os sentidos atribuídos em suas culturas às ações apresentadas pelo Programa Mobral Cultural na comunidade sertaneja, a partir das maneiras de fazer o que nas palavras de Certeau (2011, p. 41), "[...] constituem as mil práticas pelas quais usuários se reapropriam do espaço organizado pelas técnicas de produção sociocultural”.

Considerando a ausência de memória escrita no estado de Alagoas, sobre a educação como todo e, especificamente, da EJA, realidade também percebida em pesquisas anteriores ${ }^{4}$, buscamos na história oral, enquanto metodologia de pesquisa apresentada nos depoimentos dos sujeitos a compreensão de contextos históricos, guardados nas lembranças dos que vivenciaram as ações do Mobral Cultural, em um contexto histórico marcado pelas imposições da Ditadura civil-militar (1970-1985).

Afirmamos que a reconstrução de fatos históricos, em relação ao Mobral Cultural, no sertão alagoano, consistiu: "[...] em realizar entrevistas gravadas com pessoas que [puderam] testemunhar sobre acontecimentos, conjunturas, instituições, modos de vida ou outros aspectos da história contemporânea" (CPDOC $\left.{ }^{5}\right)^{7}$. Essas entrevistas foram do tipo temática, que se dedica "[...] prioritariamente sobre a participação do entrevistado no tema escolhido" (ALBERTI, 2008, p. 175). Nesse contexto, ganhou espaço a oralidade como instrumento capaz de estabelecer uma relação entre a teoriaprática ${ }^{6}$, recorrendo à história para compreensão dos conceitos de história e memória e as formas como estas se relacionaram.

$\mathrm{Na}$ pesquisa articulamos as fontes orais - fotografias, que aparecem no decorrer deste texto - que são consideradas imagens narrativas atreladas a outras narrativas das fontes orais que compôs o estudo realizado. Utilizamos o conceito de narrativas a partir dos postulados teóricos de Benjamin (2012, p. 220) para quem, diferentemente da informação, que só tem valor enquanto é novidade, a narrativa "[...] não se esgota jamais. Conserva suas forças e depois de muito tempo ainda é capaz 


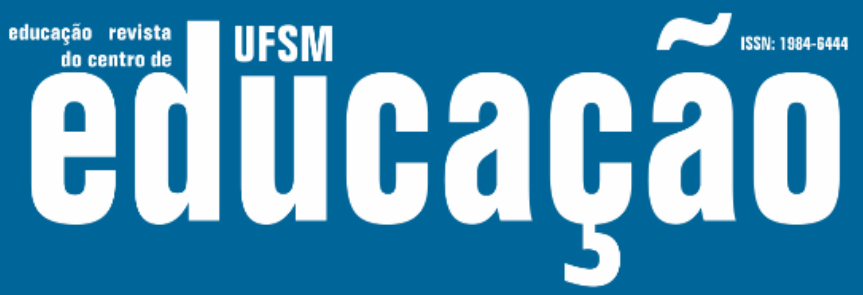

ISSN: 1984-6444 | http://dx.doi.org/10.5902/1984644437025

de desdobramentos". Nessa direção temos como objetivo, neste artigo, apresentar as narrativas sobre o Programa Mobral Cultural no âmbito do sertão de Alagoas, com o desígnio de reconstrução da memória em EJA.

Este texto compõe-se de três partes. Na primeira, ocupamo-nos em apresentar considerações sobre o Mobral Cultural. Na segunda parte, destacamos as fontes orais e visuais, constituídas de narrativas que, interpretadas pelos pesquisadores, dentro de um contexto de horizontalidade, compõem novas histórias. E, por fim, apresentamos os partícipes da pesquisa, destacando suas trajetórias e experiências. Comentamos as narrativas, que por nós interpretadas, compõem novas histórias a partir das fontes orais e visuais, que demonstraram os significados do Mobral Cultural, no Sertão alagoano.

\section{Considerações sobre o Mobral cultural}

No âmbito da educação de adultos, o governo em contexto da ditadura civilmilitar criou em 1967 o Movimento Brasileiro de Alfabetização (Mobral), implementado apenas em 1970, com um Programa de Alfabetização Funcional (PAF), que perdurou até 1985.

O projeto da ditadura civil-militar passava pelo alargamento do avanço capitalista na constituição do país pela industrialização e, por isso mesmo, necessitava de mão de obra qualificada - o que incluía maior escolarização e redução do analfabetismo entre a mão de obra industrial - para que atraísse multinacionais e que dessem conta de "retirar o Brasil do atraso histórico" a que estava submetido. Esse projeto passava, também, pela melhoria dos níveis de escolarização de jovens e adultos, historicamente interditados do direito à educação no país. O caminho primeiro, inegavelmente, era o de aprender a ler e escrever para que, deixando de serem analfabetos, homens e mulheres pudessem atender aos requisitos do capital $\mathrm{e}$ da mão de obra trabalhadora.

O Mobral Cultural teve seu lançamento em 1973 na perspectiva de educação permanente que o Movimento defendia, e era voltado para o desenvolvimento de ações culturais, e procurava envolver os mobralenses advindos do PAF e de outra iniciativa denominada Programa de Educação Integrada (PEI). Havia o entendimento 


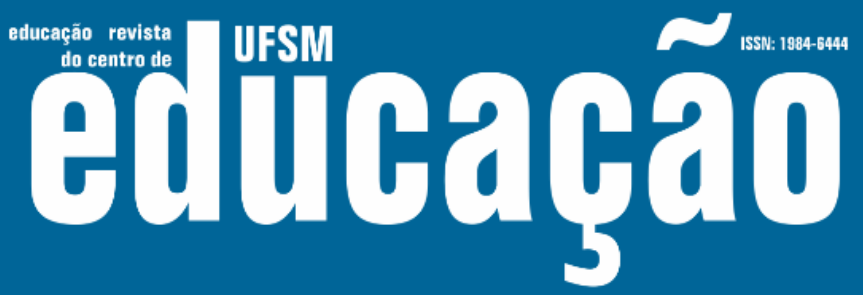

ISSN: 1984-6444 | http://dx.doi.org/10.5902/1984644437025

de que a atuação dessas pessoas não deveria limitar-se à sala de aula. Buscava, com isso, a integração dos que passaram pelo processo de alfabetização e na continuidade dos estudos; bem como a comunidade em geral, a partir da valorização das expressões culturais que estes sujeitos possuíam. Concebia a ação cultural como "Complementação da ação pedagógica, preenchimento sadio das horas de lazer e valorização ou descoberta das potencialidades criativas do homem" (CORRÊA, 1979, p. 241-242).

Explica Vanilda Paiva (2003, p. 382) que os programas do Mobral foram estratégias de sobrevivência institucional do órgão, que encontrava legitimidade e autonomia na vigência dos governos autoritários: "Um grande sistema de educação permanente a serviço da segurança interna do regime e do sistema de dominação era a grande tarefa do Mobral".

As ações do Mobral Cultural norteavam-se nos princípios de "democratização" da cultura, dinamização da criatividade e intercâmbio cultural e valorização do homem e da cultura local (CORRÊA, 1979). Sua estrutura operacional funcionava em três níveis de atuação: nacional, estadual e municipal e desenvolvia suas atividades por meio de duas unidades operacionais: o Posto Cultural e a Mobralteca.

\section{Fontes orais e visuais: alguns achados}

O aparecimento das fotografias no momento das entrevistas ajudou-nos a perceber a necessidade dessa interação entre as fontes visuais - fotografias - e as fontes orais - com os depoimentos memorialísticos dos sujeitos que participaram do fato histórico, no caso específico as ações do Mobral Cultural.

A interação das fontes orais com outras fontes - as fotografias -, traz a composição de uma rede documental, justificando que "[...] deve-se ter em mente [...] outras fontes (grifos nossos) - primárias e secundárias; orais, textuais, iconográficas etc. - sobre o assunto estudado" (ALBERTI, 2008, p. 187). A possibilidade de confrontar fontes variadas contribuiu para o enriquecimento do estudo e abriu a possibilidade de comparação das informações contidas nas fontes orais com as demais, inclusive no processo de rememoração, no decorrer da entrevista. Nessa 


\section{Autตaดูão}

ISSN: 1984-6444 | http://dx.doi.org/10.5902/1984644437025

pesquisa as fotografias são tratadas como fontes que interagem com as narrativas orais, como veremos nestes escritos.

\section{Das fontes orais}

Neste estudo as memórias são relembradas pelos depoentes, que transmitem por meio do diálogo ocasionado pelas entrevistas, narrativas de um tempo passado, evocadas pela intervenção do pesquisador. Portelli (2010) destaca a importância da interação entre pesquisador e entrevistado:

[...] a narração oral da história só toma forma em um encontro pessoal causado pela pesquisa de campo. Os conteúdos da memória são evocados e organizados verbalmente no diálogo interativo entre fonte e historiador, entrevistado e entrevistador (PORTELLI, 2010, p. 19-20).

Considerando que as lembranças são construções do presente sobre o passado, esse encontro que o autor descreve configura-se como instrumento fundamental na aquisição das informações, bem como na problematização das mesmas. O diálogo passa a ser o mediador dessa construção, o que coloca o pesquisador na posição de construtor dessas fontes, retirando-o da condição de mero coletor dos relatos. Nesse sentido, a história oral é descrita por Portelli (2010, p. 210) como "uma narração dialógica que tem o passado como assunto e que brota do encontro [...]" de um sujeito que o autor denomina de narrador e outro sujeito denominado pesquisador.

Privilegiamos, nestes escritos, as narrativas memorialísticas dos sujeitos sertanejos e de outros partícipes das ações do Mobral Cultural, no município de Santana do Ipanema, sertão alagoano - os narradores - que, de forma surpreendente, aprovaram as ações de um Movimento criado pela Ditadura civil-militar, no período de 1970-1985. Essas narrativas, impregnadas pela experiência, segundo Alberti (2008, p. 165), ajudam a "[...] entender como pessoas e grupos experimentaram o passado [o que] torna possível questionar interpretações generalizantes de determinados acontecimentos e conjunturas".

Visamos em todas as entrevistas interagir com os interlocutores, na intenção de permitir que contassem o que sabiam de maneira espontânea. Para tanto, realizamos as entrevistas nos locais escolhidos pelos depoentes, que duraram em 


\section{Autดaดูão}

ISSN: 1984-6444 | http://dx.doi.org/10.5902/1984644437025

média de 60 minutos a três horas. Apesar do estudo não apresentar um número muito grande de entrevistas, é importante salientar que foram longas e interativas.

Todas as entrevistas foram gravadas, na intenção de não perder a originalidade das falas, seguindo orientações de Thompson (1992, p. 146), que ensina que a gravação apresenta uma grande vantagem sobre os demais registros, pois nela:

Todas as palavras empregadas estão ali exatamente como foram faladas; e a elas se somam pistas sociais, as nuances da incerteza, do humor ou do fingimento, bem como a textura do dialeto.

Com o intuito de aproveitar da melhor maneira possível as relevantes informações contidas nas falas dos sujeitos entrevistados, nós procuramos compreender e interpretar os fenômenos em estudo, e levamos em consideração os contextos nos quais os sujeitos da pesquisa se inserem, e fizemos constantemente a organização do material coletado, tendo como base o objetivo da pesquisa.

No que diz respeito à interpretação, vivenciamos no decorrer dessa pesquisa os aspectos que as fontes orais permitem ao pesquisador, sobretudo no momento da entrevista: aproximação da subjetividade do entrevistado, o encontro face a face que possibilitou a apreciação de detalhes imperceptíveis em outras fontes. Detalhes que enriquecem a pesquisa, pois nesses momentos o pesquisador tem a oportunidade explorar essa subjetividade. Por essa razão a história oral distingue-se de outros escritos de "[...] que buscam legitimar-se ocultando o papel do pesquisador na constituição das fontes, como se elas existissem por si, em vez de ser produto do encontro dialógico" (PORTELLI, 2010, p. 217). Vivenciamos esse encontro, marcado pela interação entre o pesquisador e os seus depoentes; encontro fortuito para a análise dos dados e interpretação do fato histórico.

\section{Das fontes visuais}

Fixada na fotografia, a memória de um instante é preservada, guardada como um tesouro que carrega em si a preciosidade de um tempo que não se resgata, mas se reconstrói a partir das imagens que evidencia características de um acontecimento histórico: e possibilita o aguçamento da imaginação dos que não viveram tal momento, 


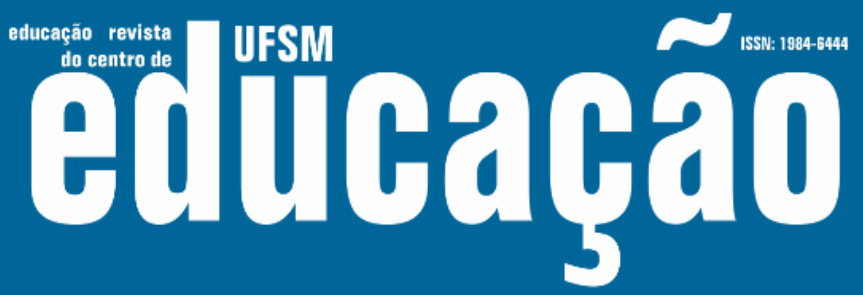

ISSN: 1984-6444 | http://dx.doi.org/10.5902/1984644437025

bem como o reencontro de um passado presente nas lembranças dos sujeitos que protagonizaram o fato histórico.

Os escritos de Cartier-Bresson (1971) traduzem o valor da fotografia no processo de reconstrução do passado, por meio da memória imagética que traz em sua essência fragmentos de um passado que pode ser revisitado a partir da imagem. Dessa forma, entendemos que entre os meios de expressão existentes, a fotografia se sobressai, uma vez que "[...] é o único que fixa para sempre o instante preciso e transitório [...]" (CARTIER-BRESSON, 1971, p. 21). Trata-se da retenção de momentos que não voltarão a acontecer e que, por mais que fiquem gravados nas lembranças dos que os vivenciaram, não serão possíveis de ser revelados, porque as memórias dos protagonistas da história não são reveláveis em laboratórios fotográficos.

As imagens que apresentamos nesta pesquisa são grafadas pelas histórias dos sujeitos sertanejos em seus espaçostempos. São imagens que dão identidade a um contexto histórico e fazem soar novas interpretações aos que contam com essa memória para o entendimento da história, dado que fixam no papel um instante único. Entendemos que a fotografia é capaz de revelar o que o olhar não é capaz de fixar, possibilitando uma análise mais apurada, evidenciando novas dimensões da realidade. O congelamento da imagem no ato fotográfico torna possível a revelação do que Benjamin (2012, p.101) chamou de "inconsciente ótico". No texto Pequena história da fotografia, o autor observa:

[...] a fotografia revela [...] os aspectos fisionômicos, mundos de imagens habitando as coisas mais minúsculas, suficientemente ocultas e compreensíveis para encontrarem um refúgio nos devaneios, e que agora, tornando-se grandes e formuláveis, mostram que a diferença entre a técnica e a magia é uma variável totalmente histórica.

A captação das minuciosidades por meio das imagens fotografadas permitiu, no percurso que vivemos, o aguçamento do nosso olhar na análise que ora realizamos do acontecimento histórico investigado, que nos possibilitou admitir novas interpretações acerca de um passado que, em um instante fora fixado na imagem capturada. Isso nos fez lembrar Mauad (1996), ao apresentar seus estudos sobre as 


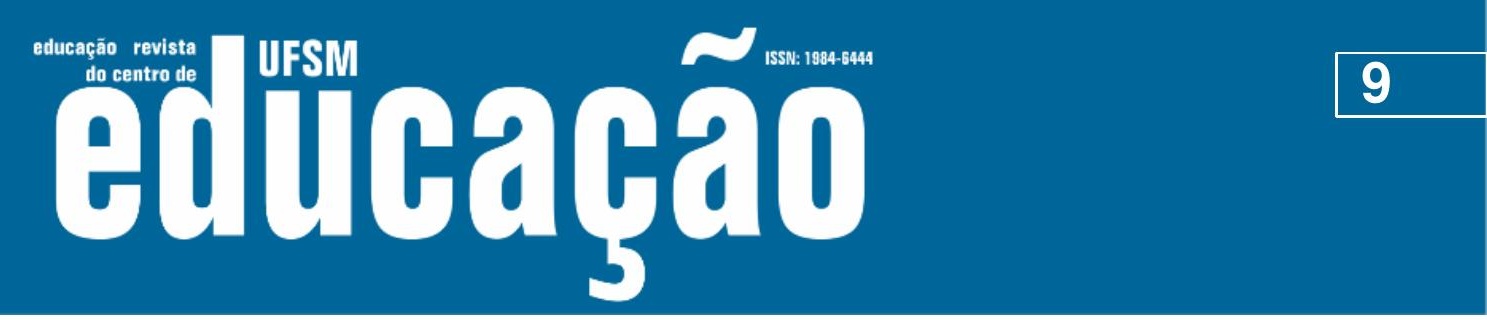

ISSN: 1984-6444 | http://dx.doi.org/10.5902/1984644437025

interfaces da fotografia na reconstrução da história, ao enfatizar que a interpretação da fotografia resulta da produção de sentidos que Ihes são atribuídos.

Tal perspectiva remete ao circuito social da fotografia nos diferentes períodos de sua história, incluindo-se, nesta categoria, todo o processo de produção, circulação e consumo das imagens fotográficas. Só assim será possível restabelecer as condições de emissão e recepção da mensagem fotográfica, bem como as tensões sociais que envolveram a sua elaboração. Desta maneira, texto e contexto estarão contemplados (MAUAD, 1996, p. 8).

Esse circuito social da fotografia possibilita a percepção das mensagens presentes nas imagens e o contexto social de sua captação, visto que "[...] são resultado de um jogo de expressão e conteúdo que envolvem, necessariamente, três componentes: o autor, o texto propriamente dito e um leitor" (MAUAD, 1996, p. 8). Nesse sentido, a imagem fotográfica enquanto texto permite aos leitores novas interpretações do passado registrado pela câmera que captura, a partir do olhar do fotógrafo, a imagem que lhe convém, que Ihe chama mais a atenção, como é o caso da fotografia a seguir.

Figura 1 - Apresentação de banda de pífanos - julho de 1982.

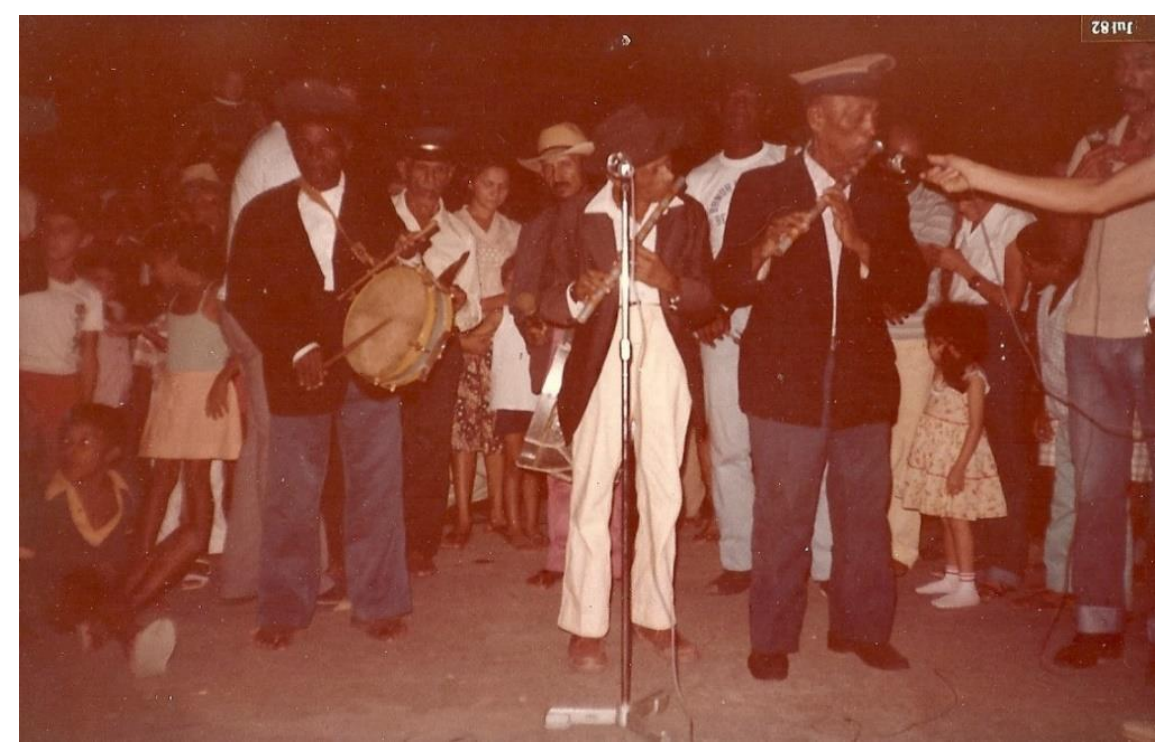

Fonte: Arquivo pessoal de José Petrucio de Oliveira Silva.

A fotografia, datada de 1982, registra o momento de uma das várias apresentações culturais mobilizadas pelo Mobral Cultural no sertão alagoano, bem 


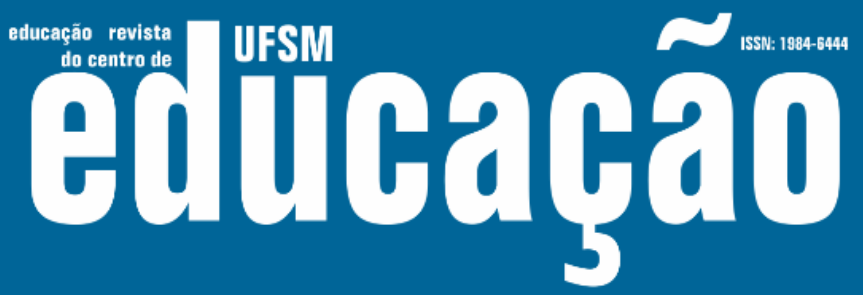

ISSN: 1984-6444 | http://dx.doi.org/10.5902/1984644437025

como em diversas comunidades do interior do estado, o que nos permitiu realizar a bricolagem (CERTEAU, 2011), por entender que a fotografia trouxe em si narrativas que permitiram, junto às fontes orais, fazer a leitura dessa imagem.

Considerando a capacidade de a câmera fotográfica capturar, em um instante: imagens ricas em narrativas que demonstram os artefatos culturais de uma comunidade, como o seu povo se comporta e aprende a partir de situações como as que são captadas na Figura 1, dizemos que essa imagem, em específico, traz registros compositores de narrativas históricas sobre a cultura popular, sobre um conjunto ${ }^{7}$ de música típico do Nordeste, que combina uma sonoridade composta por pífanos e percussão, indispensáveis nos festejos das comunidades durante as festas religiosas. Em especial nas festas dos padroeiros e nas novenas, acompanhando as procissões pelas ruas das cidades "tirando esmola para o santo" e chamando a atenção dos moradores da comunidade, sobretudo, as crianças.

Entendendo as fotografias enquanto disparadoras de outras narrativas que vão além das narrativas orais destacamos, sobretudo, o que dizem as imagens pelos seus elementos constitutivos em termos de iconografia. Para isso, Leite (1993, p. 149) afirma ser necessário o aguçamento da sociabilidade para a percepção das narrativas contidas nas fotografias, uma vez que "Não se procura na fotografia apenas o que comprove as análises históricas verbalizadas, mas sim informações, dimensões e relações que as verbalizações não têm condições de proporcionar".

Esse estudo conseguiu reunir um corpus documental composto por 87 fotografias, caracterizado por imagens diversas que apresentam comportamentos fotográficos variados, em grande maioria de profissionais desconhecidos na atualidade. Dessas, selecionamos apenas aquelas que se apresentam narrativas mais consistentes para essa pesquisa, ou seja, as imagens relacionadas às ações culturais do Mobral, haja vista que boa parte das fotografias é relacionada aos demais programas implantados pelo Movimento, e poderão ser utilizadas como fontes em outras pesquisas.

Todas as fotografias fazem parte do conjunto de memórias do acervo pessoal dos entrevistados e foram cedidas no momento das entrevistas e disponibilizadas para publicação. Os estudos de Leite (1993, p. 165) mostram que essa categoria de 


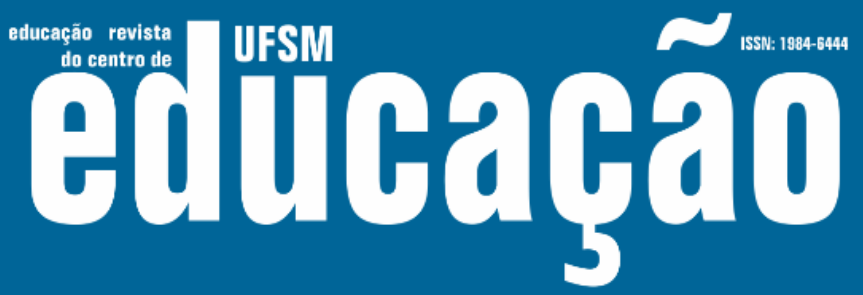

ISSN: 1984-6444 | http://dx.doi.org/10.5902/1984644437025

imagens tem grande valor, uma vez que "Feita para recordar atos da vida, em sua continuidade, está carregada de conotações tanto mais fortes quanto mais condicionadas pelo mundo exterior".

Os depoimentos dos sujeitos partícipes das ações do Mobral Cultural encontram no acervo fotográfico apoio fundamental para rememorá-lo. O aparecimento das fotografias no momento das entrevistas ajudou a perceber a necessidade da interação entre essas duas fontes. Do mesmo modo, as fotografias ganham novos sentidos a partir das narrativas que os sujeitos a elas atribuem quando as analisam.

\section{Contribuições e ressignificações em torno das ações culturais do Mobral: múltiplos olhares.}

As trilhas da oralidade conduziram-nos às pessoas que trabalharam na Coordenação Estadual do Mobral em Alagoas - um ex-animador das atividades culturais, três ex-supervisoras estaduais e duas ex-agentes pedagógicas. Localizamos, também, em nossas incursões, alguns sertanejos, sendo: um artista que se apresentava nos palcos da Mobralteca e um ex-aluno do Programa de Alfabetização Funcional que narrou sua experiência enquanto espectador da Mobralteca; e ainda na região sertaneja gravamos as narrativas de dois exsupervisores de área. Esses sujeitos compõem o quadro de interlocutores dessa investigação. Contribuíram cada um à sua maneira, na construção das histórias que são contadas no decorrer deste texto.

As narrativas que aparecem nestes escritos, para além da informação, estão preocupadas com a interpretação que cada leitor fará ao analisá-las, entendendo como Benjamin (2012, p. 219) que o leitor é livre "[...] para interpretar a história como quiser, e com isso o episódio narrado atinge uma plenitude [...]”. A nossa preocupação com a legitimidade das narrativas é oriunda do entendimento que temos delas como uma arte, que nas palavras do pensador encontra-se em extinção.

Corroborando os escritos de Benjamin (2012), os estudos de Bosi (1994, p. 85) esclarecem o valor das narrativas ao dizer: "A arte da narração não está confinada 


\section{工 Futlagha}

ISSN: 1984-6444 | http://dx.doi.org/10.5902/1984644437025

nos livros, seu veio épico é oral. O narrador tira o que narra da própria experiência e a transforma em experiência dos que escutam". É nessa perspectiva de respeito às experiências vividas e agora narradas, que buscamos a composição de novas histórias sobre a atuação do Mobral Cultural, no sertão de Alagoas.

As pistas levaram-nos a um grupo de senhoras que trabalharam na Coordenação Estadual do Mobral. Apesar de não pertencerem à região sertaneja, suas narrativas foram importantes, uma vez que permitiram uma multiplicidade de olhares que enriqueceram a investigação, ao mesmo tempo em que ajudaram a compreender os significados e contribuições das ações propiciadas pelo Programa.

As lembranças das interlocutoras, em um primeiro momento, foram de valorização do trabalho efetivado pelo Movimento, considerado inédito na região sertaneja. Nesse sentido, destacamos a narrativa que se segue:

O Mobral foi uma grande oportunidade para essas e outras pessoas pobres, porque veja bem, o pessoal da zona rural! A gente enfatiza mais o pessoal da zona rural, né? Eram pessoas marginalizadas, não existia esse acesso que existe hoje, a área da saúde mesmo foi o Mobral que chegou até lá. Hoje a gente tem o Programa de Saúde da Família que vai até lá, em 70 o Mobral era que fazia isso, à sua maneira. [...] o que chamava mais a atenção era a Mobralteca, porque o Posto ele agregava, a gente tinha uma Comissão e a Comissão se ela fosse dinâmica ela conseguia fazer um trabalho maravilhoso. (MARIA ROSA DOS SANTOS CAVALCANTE - EXSUPERVISORA ESTADUAL).

Os fatores lembrados pela ex-supervisora estadual denunciam as condições sociais, políticas e econômicas que permeavam a comunidades sertaneja no contexto em estudo, marcadamente pela ausência de políticas públicas nessa área. A depoente denuncia um modelo social que, historicamente, definiu como campo de marginalização o espaço reservado aos sujeitos das classes populares, em que o público da EJA encontra-se inserido e, no caso específico, os sujeitos sertanejos. Os escritos de Santos (2012) denunciam essa marginalização, essa negação dos direitos básicos dos cidadãos brasileiros, sobretudo os mais pobres:

Olhando-se o mapa do país, é fácil constatar extensas áreas vazias de hospitais, postos de saúde, escolas secundárias e primárias, informação geral e especializada, enfim áreas desprovidas de serviços essenciais à vida social e à vida individual. O mesmo, aliás, se verifica quando observamos as plantas das cidades em cujas periferias, apesar de certa densidade demográfica, tais serviços estão igualmente ausentes. É como se as pessoas nem lá estivessem (SANTOS, 2012, p. 59). 


\section{工 Tusm Eutoabुa}

ISSN: 1984-6444 | http://dx.doi.org/10.5902/1984644437025

Nas décadas em estudo, o sertão era uma dessas "áreas vazias", o que autoriza a interlocutora a dizer que o Mobral, com os seus programas, tornou-se uma grande oportunidade para os sertanejos marginalizados. A ausência de políticas públicas também aparece nas narrativas de outra ex-supervisora estadual. A entrevistada aponta o descaso com as poucas escolas existentes nas comunidades sertanejas:

Eu trabalhei num município onde tinha o ginásio [correspondente aos atuais últimos anos do ensino fundamental] e não tinha sequer uma biblioteca, então o único lugar do aluno daquela escola pesquisar era no Posto Cultural do Mobral, porque o Mobral tinha o material, não era um material tão rico, era um material básico aí eles procuravam esse posto cultural para fazer pesquisa. Ele era um ponto de apoio nesta área para a comunidade de um modo geral. (MARIA DO CARMO CABRAL DE ARAÚJO - EXSUPERVISORA ESTADUAL).

As precárias condições do campo educacional levam as interlocutoras a creditarem as ações desenvolvidas pelo Mobral Cultural como positivas. Esses créditos vão desde a oferta de Programa de Saúde, material básico de pesquisa no Posto Cultural da comunidade "não tão rico", às ações de valorização da cultura das comunidades. Os depoimentos nos disseram explicitamente as benesses do Movimento, que supria as carências deixadas pelo Estado.

Os trechos elencados a seguir apontam mais diretamente para o trabalho que era desenvolvido no campo da cultura. As vozes trazem em seu âmago as interpretações dos fatos vivenciados pelas entrevistadas, suas experiências, suas emoções, fatores que as motivaram a compartilhar suas narrativas.

O Mobral Cultural tinha um trabalho excelente, ele resgatou o trabalho cultural praticamente de todo o estado de Alagoas, ele valorizava o artesão, o músico, inclusive existia o concurso de banda de pífano, as rendeiras, a primeira vez que as rendeiras começaram a se apresentar em feira foi depois do Mobral. O Mobral é que fazia isso, sem contar quando a Mobralteca vinha, além dos concursos que eram feitos na praça. (CARMÉLIA MARIA B. ANDRADE - EXAGENTE PEDAGÓGICA /APEDE).

[...] ele atingia tudo, desde a alfabetização até a parte cultural, a saúde, nós tivemos até a horta comunitária! Eu me lembro que em Água Branca eu fui fazer uma supervisão e um senhor veio me perguntar como usar a camisinha, veja há quantos anos atrás, o Mobral já trabalhava isso, o controle da natalidade. Não é uma alfabetização? (MARIA ANUNCIADA DE MELO TORRES - EX-AGENTE PEDAGÓGICA/APEDE).

Não externaram os depoimentos as intencionalidades ideológicas do Movimento e fazem alusões ao Mobral como um órgão destinado a atender, no campo 


\section{Autนaดูลิ}

ISSN: 1984-6444 | http://dx.doi.org/10.5902/1984644437025

da educação de adultos, os propósitos desenvolvimentistas que caracterizavam seu surgimento e vigência. Os reais propósitos da criação e implantação do Movimento são assim explicados por Jane Paiva (2009, p. 166).

Não se criava toda uma estrutura de atendimento que chegava, com certeza, a todos os municípios brasileiros para conferir o direito de todos à educação. Chegava-se porque o analfabetismo era um mal, a chaga a ser curada, responsável pelo atraso do processo produtivo e industrial, sem o que o país não ingressaria no clube dos desenvolvidos.

A narrativa presente no segundo excerto, para além das considerações valorativas das ações culturais, traz um conceito ampliado de alfabetização, quando a interlocutora questiona se a orientação de um adulto sobre os cuidados básicos que envolvem o uso de preservativo, como controle da natalidade: "não é uma alfabetização"? Esse questionamento demonstra, enquanto contribuição do Movimento, a relevância da circulação de informações básicas no sertão alagoano. Demonstra, principalmente, que as práticas de alfabetização não podem ser meramente técnicas.

Os fatos lembrados por outra interlocutora que tinha sua atuação no Programa de Profissionalização do Mobral revelam a função do Posto Cultural como elemento articulador entre os programas. A entrevistada falou sobre a parceria que mantinha com as empresas e o treinamento dos trabalhadores que se iniciava com 0 recenseamento destes no Balcão de Empregos:

Era uma parceria com a empresa, o instrutor era da empresa, quem
apresentava o trator, por exemplo, era a empresa. Aí nós tínhamos além de
treinamento, nós tínhamos o balcão de emprego e tudo isso funcionava no
Posto Cultural. Tudo isso era feito lá no Posto Cultural, era o polo de encontro
de todos os programas. Vinha também curso de artesanato era também no
Posto Cultural, isso em atendimento a alunos e comunidade. Todo o trabalho
era assim, sempre aberto à comunidade. Eu lembro de vários trabalhos que
desenvolvíamos no sertão, em Dois Riachos [...] em todos os municípios do
sertão tinha esse tipo de trabalho que tinha sua organização dentro do Posto
Cultural. (MARGARIDA SOUZA DE ARAÚJO - ÁREA DE
PROFISSIONALIZAÇÃO).

A amplitude do Mobral também aparece no depoimento dessa interlocutora, quando se refere às múltiplas ações desenvolvidas: "Aí o aluno não ia só se alfabetizar, mas ele tinha esse leque de outras ações". As ações a que se refere a 


\title{
工 Tusm Futbabुa
}

ISSN: 1984-6444 | http://dx.doi.org/10.5902/1984644437025

depoente são hoje assumidas pelas Secretarias Municipais do Trabalho e de Ação Social, que realizam programas sociais, órgãos que à época não existiam.

Rompendo com o silêncio de décadas, as lembranças do ex-animador das ações culturais do Mobral foram evocadas a contribuir no processo de reconstrução da história. As narrativas do interlocutor trazem fragmentos de memórias escondidas no esquecimento provocado pelo silenciamento de um Movimento, que serviu aos propósitos da ditadura civil-militar. Para Certeau (2011, p. 146), a memória permanece escondida em lugares imprevistos "[...] até o instante que se revela, no 'momento oportuno', de maneira ainda temporal embora contrária ao ato de se refugiar na duração. O resplendor dessa memória brilha na ocasião".

Passadas mais de quatro décadas, as memórias do ex-animador encontraram na temporalidade do presente o momento oportuno para romper o silêncio e contribuir na reconstrução dos acontecimentos. O depoente mostrou-se um dos maiores conhecedores das ações culturais do Mobral nos municípios do sertão alagoano, visto que a função por ele assumida colocava em contato direto com as comunidades mais isoladas do estado.

Quando questionado sobre a relevância das ações culturais nas comunidades do sertão alagoano, o interlocutor, conforme segue, também apresentou um depoimento valorativo das iniciativas do Mobral no campo da cultura. Destacou principalmente o fato de o Movimento chegar até os sertanejos, sobretudo, aos que moravam nas comunidades rurais.

\begin{abstract}
Eu acho que levar tudo isso até eles foi o mais importante! Eu acho que eles aprendiam também com o que a gente falava, eles viam ali, acho que eles aprendiam e compreendiam, a gente percebia que eles riam! Eles prestavam a atenção naquilo que a gente falava. E só em bater palma, você percebia a participação deles por estar ali [...] era uma coisa que animava, era muito bonito.
\end{abstract}

Era para os alunos do Mobral e para a comunidade em geral. Os alunos eram mobilizados para vir para aquele local e fora aquelas pessoas que estavam ali, que já moravam ali. Não era especificamente só para os alunos do Mobral não, era para a toda a comunidade que quisesse estar ali naquele momento. Era como se fosse uma festa, você via [...] olhava para cara de cada um, você não via cara feia, via alegria! (JOSÉ PETRUCIO DE OLIVEIRA SILVA).

A ênfase no depoimento vai para a receptividade com que os sertanejos acolhiam as ações culturais do Mobral. A alegria e a interatividade aparecem nos 


\section{工 Tusm Eutibabat

ISSN: 1984-6444 | http://dx.doi.org/10.5902/1984644437025

dadas. Faziam das "[...] representações ou leis que Ihes eram impostas outra coisa que não aquela que o conquistador julgava obter por elas".

Em busca das contribuições e significados das ações culturais do Mobral em terras do sertão alagoano no período de 1973 a 1985, abrimos espaços para as narrativas dos sertanejos que vivenciaram tais ações. Nesse espaço, serão privilegiados os depoimentos da ex-supervisora de área de Santana do Ipanema e do ex-supervisor de um município vizinho, bem como as lembranças de dois sertanejos que vivenciaram a experiência a partir de perspectivas diferentes, sendo um como seguidor da Mobralteca e o outro como espectador.

Quando se referiu à importância das ações culturais do Mobral, a exsupervisora de área de Santana do Ipanema relembrou que a mobilização representava também como já apareceu no depoimento do ex-animador, uma festa para o município sede e para as comunidades vizinhas.

Era uma festa por que observe o seguinte! Uma cidade do interior era uma cidade que não tinha muitas novidades, muitas opções [...] e a Mobralteca chegava ficava na cidade, era um carro grande, bem equipado, com palco com microfone [...] então a gente tinha que mobilizar o povo da cidade para ir, para participar [...] e, além disso, a gente ainda falava com os prefeitos para trazer as pessoas de outros municípios para cá. Era no mínimo um show! Hoje trazem artistas famosos, naquela época traziam os artistas da terra e todo mundo saía de casa para assistir (JENIUZA SOARES DE MELO).

Brandão (1989, p. 5), ao falar sobre as festas de rua que tradicionalmente ocorrem em cidades pequenas do interior, ajuda a entender o significado das duas noites de festa em uma cidade do sertão alagoano, enfatizadas pela narradora como no "mínimo um show"! O autor permite uma análise mais ampliada das festas populares quando apresenta a festa como uma bricolagem das manifestações populares, ao dizer:

[...] a festa é justamente essa bricolagem de ritos, folguedos e festejos de devoção e de pura e simples diversão. Bailes e forrós, pagodes antigos e danças de catira ou jungo concorrem com as apresentações mais modernas de 'shows sertanejos' e rodeios, com escolhas de Rainha da Festa (BRANDÃO, 1989, p. 5).

A entrevistada apontou ainda que, no município de Santana do Ipanema, à época, existiam poucas atividades ligadas à valorização da cultura popular. Nesse 


\section{$\sim$ usm Eulloab̧a}

ISSN: 1984-6444 | http://dx.doi.org/10.5902/1984644437025

sentido, afirmou que o Mobral Cultural "resgatou" ao valorizar as tradições da localidade.

[...] em aspectos assim, por exemplo, eu moro em Santana do Ipanema, aí a gente fazia um planejamento para apresentar na Mobralteca. O que é que Santana do Ipanema tem para apresentar, ou eu formaria um grupo para ensaiar ou então eu ia atrás dos que já existiam, não é o resgatar? [...] pessoas da comunidade, se tivesse um reisado, um pastoril, os repentistas também se apresentavam, aí a gente fazia aquela programação para aquele dia. Aí como Santana do Ipanema era polo, como eu tinha minhas colegas de outros lugares [...] trazia os talentos de outros municípios. (JENIUZA SOARES DE MELO).

A partir dos depoimentos da interlocutora, é possível perceber que a cultura do povo sertanejo tem uma lógica própria e apresenta peculiaridades que se assemelham às descrições que Brandão (1989) faz sobre as festas.

O trabalho com fontes orais exige do pesquisador a perseguição das pistas que surgem no decorrer da imersão no campo de investigação. As trilhas seguidas nesse trabalho conduziram-nos para além dos limites geográficos de Santana do Ipanema. Por se tratar de um Movimento presente em todos os municípios, foi recorrente a indicação de pessoas de comunidades vizinhas que participaram das atividades culturais do Mobral em seus municípios de origem e em municípios da vizinhança.

Nas incursões pelo campo de pesquisa tivemos a oportunidade de entrevistar Hélio Silva Fialho, ex-supervisor de área do município de Pão de Açúcar, situado a aproximadamente $50 \mathrm{~km}$ de Santana do Ipanema. O interlocutor, assim como os demais, contribuiu de forma significativa na rememoração das ações culturais desenvolvidas pelo Mobral no sertão alagoano. Suas lembranças trazem muitos aspectos da memória coletiva do povo sertanejo. Nas palavras de Halbwachs (2006, p. 61), "[...] a representação das coisas evocada pela memória individual não é mais que uma forma de tomarmos consciência da representação coletiva relacionada às mesmas coisas".

As palavras proferidas pelo depoente são entendidas como emprestadas de um contexto experienciado não apenas por ele, mas por um significativo grupo de pessoas do sertão de Alagoas. Nesse processo de rememoração mediado pela entrevista, os relatos orais do ex-supervisor de área também caminharam na 


\section{$\sim 7$ oltibarat}

ISSN: 1984-6444 | http://dx.doi.org/10.5902/1984644437025

perspectiva do entendimento das ações como positivas para os sertanejos, porque essas ações conseguiram chegar até as pessoas:

Eu vejo como de resgate! O Mobral apesar de ter sido criado na Ditadura civilmilitar [...], mas você sabe como é a política coronelista! Vamos colocar nestes termos, a política dos coronéis do sertão é não ensinar a ninguém, absolutamente nada, para que essas pessoas permaneçam na subserviência, o Mobral vinha para justamente abrir as cabeças dessas pessoas. (HÉLIO SILVA FIALHO).

Esse depoimento do interlocutor permite uma análise das contradições do contexto histórico marcado pela Ditadura civil-militar, do sertão alagoano e da presença do coronelismo. Para ele o Mobral, criado com a perspectiva de dominação, abria uma possibilidade que nas palavras do depoente "vinha para justamente abrir a cabeça dessas pessoas", enquanto que "[...] a política dos coronéis do sertão é não ensinar a ninguém, absolutamente nada, para que essas pessoas permaneçam na subserviência".

O tom enfático que o entrevistado empregou em suas palavras expressou sua vontade de falar sobre um passado ainda presente em terras do sertão e que para ele chegou bem antes da Ditadura, acrescentando: "[...] outra forma de coerção, bem mais antiga [...] o coronelismo". Coronelismo esse que tem suas origens na dominação do povo por meio do mecanismo da dependência pessoal, ainda recorrente nas pequenas cidades e meio rural do sertão alagoano.

Dantas (1987, p. 15), ao apresentar a dimensão ideológica da dominação, traz a seguinte caracterização:

[...] um conjunto de ideias e representação, muitas vezes veiculadas através
de normas que reforçam laços de lealdade e práticas de submissão. Dentro
de um universo semifechado o controle das informações pelo senhor se torna
elemento vital para a preservação dos padrões de dominação e manutenção
das relações de dependência pessoal.

Nessa mesma perspectiva, Freire (2011, p. 59) fala sobre o latifúndio como uma estrutura de poder que inferioriza as pessoas; por não terem posse das terras, são obrigadas a se submeter com obediência aos senhores proprietários dessas terras. "A estrutura latifundista, de caráter colonial, proporciona ao possuidor de terra, pela força e prestígio que tem a extensão de sua posse também até os homens". 


\title{
工 Autlaba
}

ISSN: 1984-6444 | http://dx.doi.org/10.5902/1984644437025

No nosso entendimento, o fato do interlocutor ter vivenciado a condição de controle social imposta pela "política dos coronéis do sertão" autorizou-o a fazer comparação com as ações culturais do Mobral que, mesmo em contexto de ditadura, foram absorvidas pelos sertanejos como uma possibilidade de aprendizagens diferenciadas das práticas de submissão engendradas pela dominação dos coronéis.

A nossa preocupação em dar visibilidade às memórias dos sujeitos esquecidos pela história oficial instigou-nos a ouvir pessoas que participaram das ações culturais do Mobral em várias categorias, desde os que fizeram parte das Coordenações Estaduais e pela Comissão Municipal aos sertanejos que viveram essa experiência, apesar de não serem alunos do Mobral, como é o caso do Edgard Lima.

Os depoimentos apresentados neste estudo ancoram-se uns nos outros, e demonstram que os depoentes participaram dos mesmos eventos com perspectivas diferenciadas. Edgard Lima guarda também em suas memórias, aspectos positivos das passagens da Mobralteca pelo sertão. Traz em suas lembranças não apenas sua atuação, mas também a importância da iniciativa "para os artistas desse 'sertão afora', expressão muito usada pelos sertanejos". O interlocutor, em suas recordações, apresenta as experiências de um grupo de artistas sertanejos que, assim como ele, utilizaram o palco da Mobralteca para divulgação de seus trabalhos. Vejamos o relato:

\begin{abstract}
Na época eu não sei quem era o governo, mas foi uma ideia muito boa, não só para mim, mas para os artistas desse sertão afora! Que se apresentaram, que mostraram seu trabalho! E o melhor de tudo é a gente poder lembrar e contar essa história. Diante de tudo só quero agradecer à Mobralteca que nos deu essa oportunidade! Na época, foi muito importante para mim, para minha carreira [...] é uma história que fez parte da minha vida, e faz parte da minha vida! Foi muito importante! Foi importante porque eu não sabia o talento que eu tinha guardado dentro de mim, e a partir dali [...] pelo povo que estava me ouvindo, gostando e aplaudindo, me deu um incentivo, não de ser um cantor profissional, mas de cantar, mostrar esse talento que eu tinha guardado. A partir do momento que eu mostrei esse talento para as pessoas, as pessoas começaram a aplaudir e dizer que eu cantava bem, eu botei na cabeça que poderia ser cantor futuramente (EDGARD LIMA).
\end{abstract}

O tom que o entrevistado empregara na sua fala ao contar, com emoção, que "[...] é uma história que fez parte da minha vida, e faz parte da minha vida!", ilustra o valor da história oral como uma metodologia que "dá voz ao silêncio". No momento das entrevistas, as narrativas orais proporcionam traços da subjetividade que "[...] 


\section{F WEM Eutinapá

ISSN: 1984-6444 | http://dx.doi.org/10.5902/1984644437025

revelam as emoções do narrador, sua participação na história e a forma pela qual a história oral o afetou" (PORTELLI, 1997, p. 29).

Além de reconhecer a importância da presença da Mobralteca para os artistas do sertão, o interlocutor enfatiza o que ela representou para o desenvolvimento profissional da sua carreira de cantor. Demonstra que se apropriou da oportunidade, coisa que nem todos os seus colegas conseguiram. Segundo ele, a iniciativa representou o incentivo que precisava, haja vista que já detinha o talento.

Entre os múltiplos olhares para as ações culturais do Mobral no sertão de Alagoas, destacamos as narrativas de Edjário Vieira Souza, que participou como ouvinte das aulas do Programa de Alfabetização Funcional do Mobral, na zona rural em que residia, na década de 1970. O depoente, ao apresentar as contribuições e os significados das ações culturais do Mobral para o povo do sertão, enfatizam em primeira instância, o valor da alfabetização para as pessoas que tinham, naquele movimento de alfabetização, a primeira oportunidade de aprender a ler e a escrever.

As narrativas desse interlocutor são fortemente marcadas pela alusão aos seus conterrâneos: vizinhos, amigos e suas irmãs mais velhas que frequentavam as aulas de alfabetização de Mobral. O depoente narrou que à época já estava matriculado no "ensino regular", frequentando a escola pela manhã, e que durante a noite retornava à mesma escola acompanhando suas irmãs mais velhas para as aulas do PAF/Mobral e complementou:

A escola ficava de dois a três quilômetros de nossa casa, então todas as noites a gente se arrumava e ia. Inclusive era uma aventura, a gente criança; e a gente ia no inverno chovendo, o pessoal levava uma lona, toalha de mesa para se cobrir, e a gente ia embaixo, era uma aventura! Como na época eu tinha uns doze anos eu achava esquisito e interessante ver aquelas pessoas, com idades até de ser meu pai ou minha mãe, tentando lá aprender a fazer o nome. (EDJÁRIO VIEIRA SOUZA).

E na sequência à sua narrativa, o interlocutor contou sobre o processo de migração da sua família da zona rural para a zona urbana. Segundo ele, no final da década de 1970, seus pais, preocupados com a educação escolar dos filhos, adquiriram uma residência na cidade de Santana do Ipanema, em busca de melhores condições de vida, e deixaram para traz a cultura do campo para adaptar-se à cultura 


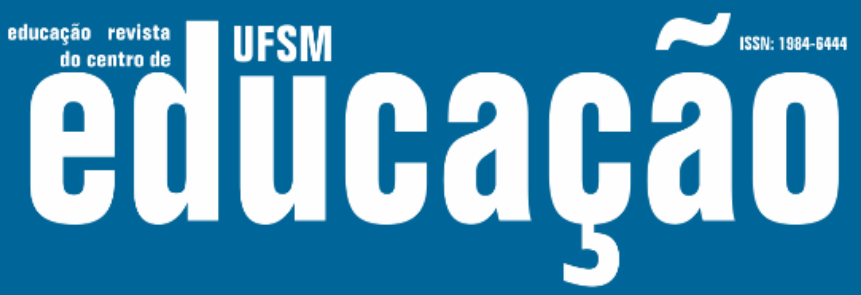

ISSN: 1984-6444 | http://dx.doi.org/10.5902/1984644437025

da cidade. Na narrativa a seguir o interlocutor descreve o seu primeiro contato com a Mobralteca:

\begin{abstract}
Para mim foi uma descoberta! [...] uma coisa assim nunca vista, primeiro por nunca ter participado nem ter visto! Era uma cidade pequena, então eu nunca tinha visto um evento naquele porte [...] E esse evento era feito ali na frente do Ginásio Santana, que a gente chama O monumento [praça central da cidade]. E nesse dia eu saí andando à noite, cedo, chegando lá eu me deparei com esse carro. Com músicas que eu não tinha assim [...] parado para ouvir. Aquele carro formato caminhão, com um palco. E nesse momento estava passando um filme, agora não me recordo qual era o filme. E tinha uma música de fundo, era uma música de Luiz Gonzaga, que me tocou até hoje essa música! Todas as vezes que ouço essa música eu lembro do evento (EDJÁRIO VIEIRA SOUZA).
\end{abstract}

O contato com a Mobralteca, assim como as demais novidades da cidade, representou para Edjário, que à época era muito jovem, um choque, proporcionado pela relação com um ambiente novo. Sua experiência deu-se na condição de espectador, que como muitos outros estavam ali para assistir às apresentações culturais que chegavam como novidade à cidade de Santana do Ipanema. Para ele, em particular, essa novidade era ainda maior, porque vinha de uma comunidade rural, na qual aquele tipo de informação não chegava.

\section{Considerações finais}

As memórias que evocamos nessa pesquisa, dos sujeitos esquecidos pela história oficial - testemunhas vivas - trouxeram novas reflexões sobre o Mobral, sobretudo, em relação ao lugar, sertão, de onde brotaram narrativas diferentes das que povoam o imaginário nacional acerca do referido Movimento. Isso nos fez perceber os múltiplos sentidos que podem ser construídos nas práticas desenvolvidas de um Movimento com a dimensão que teve o Mobral, em todo o Brasil.

Este estudo teve sua relevância na necessidade de recriação das ações do Programa Mobral Cultural no sertão alagoano, a partir da tessitura das histórias e memórias de sujeitos do sertão alagoano, sobre como experienciaram e ressignificaram ações culturais desenvolvidas pelo Mobral no contexto da ditadura civil-militar. As contribuições e ressignificações das ações culturais do Mobral apareceram das mais variadas formas, conforme os itens elencados abaixo: 


\section{Autดaคูão}

ISSN: 1984-6444 | http://dx.doi.org/10.5902/1984644437025

a. A partir da realização de concursos que envolviam folguedos da citada região, a exemplo de grupos de reisado e bandas de pífanos, mobilizados e apoiados pelas Comissões Municipais do Mobral. Esses eventos, denominados feiras culturais, aconteciam tanto nos locais de onde as músicas ou os artesanatos eram originários, como nas comunidades próximas.

b. Com destaque também para os eventos/festividades, tendo em vista apresentações de práticas culturais, os sertanejos tinham apoio do Mobral acesso a materiais tecnológicos avançados para a época e na socialização, junto a seus pares - o que tornou novas as experiências possíveis de serem vivenciadas naquele contexto histórico. Sentiam-se empoderados, considerando a visibilidade dada, conforme visualizamos nas imagens e depoimentos, porque antes essas práticas aconteciam de forma isolada e individual. Tal fato nos permitiu afirmar que houve reapropriação por parte dos sertanejos que experienciaram tais ações, recriando-as nos fios que tecem as tramas da cultura popular, durante as interações proporcionadas pelo Programa em praças das cidades e vilarejos, por meio do Posto Cultural, da Mobralteca e da Minimobralteca.

No processo dessa investigação ficou explícito que os sertanejos deste estudo deixaram-se ser invadidos pelo que não podiam controlar, mas resistiram com as múltiplas astúcias da sabedoria popular, ao mostrar o que sabiam fazer. Isso fez parte das "artimanhas" de resistência popular diante dos serviços e novidades oferecidos pelo Mobral, o que não significa dizer que o envolvimento da comunidade nas ações culturais representou a aceitação/passividade das ações apresentadas, pois quando essas ações foram implementadas, certamente já existia uma estrutura social da cultura popular alicerçada nos costumes e tradições do povo do sertão.

Destacamos, ainda, a valorização e reconhecimento dos artistas locais, sobretudo, músicos que encontraram nos palcos da Mobralteca oportunidades de mostrar seus trabalhos e iniciar carreiras profissionais pela mobilidade conferida aos artistas, que criavam coragem para se apresentarem nos municípios circunvizinhos e em outros estados do Nordeste. Foi este o caso de um de nossos interlocutores que se autodenominou seguidor da Mobralteca. Segundo interlocutores, a interação entre 


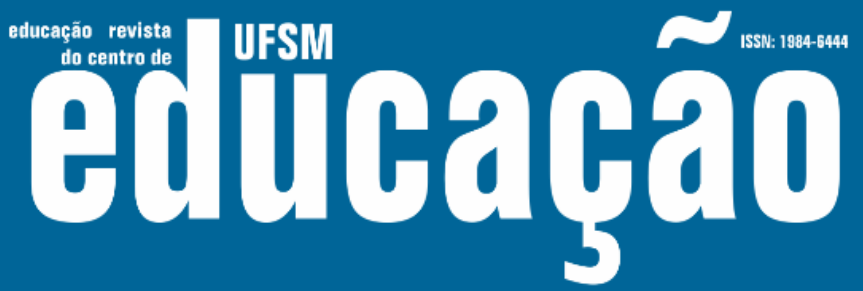

ISSN: 1984-6444 | http://dx.doi.org/10.5902/1984644437025

esses talentos possibilitava o brilhantismo da festa que conseguia reunir artistas da redondeza, muitos deles, naquele contexto, ainda anônimos.

Diante dessas oportunidades em um lugar carente como o sertão alagoano, as narrativas dos sujeitos, na rememoração de suas experiências, expressaram uma forte aceitação do Mobral. Suas falas foram sempre acompanhadas de saudosismo sobre as contribuições advindas das ações do Programa Cultural e de outras implementadas pelo Movimento nas décadas de 1970 e 1980 sem, no entanto, as situarem no contexto da Ditadura civil-militar, em plena vigência à época.

Registramos que, mesmo em situações concebidas com finalidades diversas e previamente definidas, ao visar o controle social das populações, a realidade investigada se impôs para além das estratégias políticas. Dela emergiram "táticas" cotidianas imprevistas, que invencionaram novas lógicas de apropriação do que foi oferecido aos sujeitos, que escaparam ao controle, podendo daí resultarem novas formas de significação.

\section{Referências}

ALBERTI, Verena. Histórias dentro da história. In: PINSKY, Carla B. (Org.). Fontes históricas. São Paulo: Contexto, 2008. p. 155-202

BOSI, Ecléa. Memória e sociedade: lembranças de velhos. 3. ed. São Paulo: Companhia das Letras, 1994.

BENJAMIN, Walter. Magia e técnica, arte e política: ensaios sobre literatura e história da escrita. 8. ed. São Paulo: Brasiliense, 2012. (Obras Escolhidas, v. 1).

BRANDÃO, Carlos Rodrigues. A cultura na rua. Campinas: Papirus, 1989.

CARTIER-BRESSON, Henri. "O momento decisivo". In: Fotografia e Jornalismo. Bacellar, Mário Clark (Org.). São Paulo, Escola de Comunicações e Artes (USP), 1971, pp. 19-26.

CERTEAU, Michel. A invenção do cotidiano: 1 Artes de fazer. 17. ed. Petrópolis: Vozes, 2011.

CORRÊA, Arlindo Lopes. Educação de massa e ação comunitária. Rio de Janeiro: AGGS: Mobral, 1979.

DANTAS, José Ibarê Costa. Coronelismo e dominação. Universidade Federal de Sergipe. PROEX/CECAC. 1987. 


\section{U usm

ISSN: 1984-6444 | http://dx.doi.org/10.5902/1984644437025

FILHO, Luiz Gonzaga Barros. A Banda de Pífanos. In: Boletim Alagoano de Folclore. Maceió: EDUFAL, v. 28. Jan. 1984.

FREIRE, Paulo. Extensão ou comunicação. 15. ed. São Paulo: Paz e Terra, 2011.

GERMANO. José Willington. Estado militar e educação no Brasil (1964-1985). 5. ed. São Paulo: Cortez, 2011.

HALBWACHS, Maurice. A memória coletiva. São Paulo: Centauro, 2006.

LEITE, Miriam Moreira. Retratos de família. São Paulo: Edusp, 1993.

MAUAD, Ana Maria. Através da imagem: fotografia e história interfaces. Tempo, Rio de Janeiro, vol. 1, $\mathrm{n}^{\circ}$. 2, 1996, p. 73-98.

MELO, Adriana Ferreira: O lugar-sertão: grafias e rasuras. Dissertação (Mestrado em Geografia) Instituto de Geociências, Universidade Federal de Minas Gerais, Belo Horizonte, 2006.

PAIVA, Jane. Os sentidos do direito à educação para jovens e adultos. Petrópolis: FAPERJ, DP, 2009.

PAIVA, Vanilda. História da educação popular no Brasil: educação popular e educação de adultos. 6. ed. São Paulo: Edições Loyola, 2003.

PORTELLI, Alessandro. O que faz a história oral diferente. Proj. História, São Paulo (14), fev. 1997.

PORTELLI, Alessandro. Ensaios de história oral. São Paulo: Letra e Voz, 2010.

SANTOS, Milton. O espaço do cidadão. 7. ed. São Paulo: Editora da Universidade de São Paulo, 2012.

THOMPSON, Paul. A voz do passado: história oral. Rio de Janeiro: Paz e Terra, 1992.

\section{Correspondência}

Jailson Costa da Silva - Instituto Federal de Alagoas - Campus Piranhas, Av. Sergipe, s/n - Centro Vila Sergipe, CEP 57460000, Piranhas, Alagoas, Brasil.

\section{(c) $(1)(9)$}

This work is licensed under a Creative Commons Attribution-NonCommercial 4.0 International (CC BY-NC 4.0) 


\section{N

ISSN: 1984-6444 | http://dx.doi.org/10.5902/1984644437025

\section{Notas}

${ }^{1}$ O CReMEJA tem sua história protagonizada pela Universidade do Estado do Rio de Janeiro (UERJ), desde 1996. Preserva acervos presentes e passados de diferentes contextos históricos da Educação Popular (EP) e da Educação de Jovens e Adultos (EJA). Para saber mais visite o site: http://cremeja.org/a7/.

${ }^{2}$ Utilizamos o termo Ditadura civil-militar, entendendo que o golpe de 1964 foi fruto de uma coalizão civil e militar. Confirmou-se com a ascensão de um novo bloco no poder que envolvia a articulação entre o conjunto das classes dominantes, a exemplo a burguesia industrial e financeira nacional e internacional, “[...] bem como uma camada (de caráter civil) de intelectuais e tecnocratas. $\mathrm{O}$ espectro de interesses representados por esse conjunto autoriza-nos a qualificá-lo como uma elite”. (GERMANO, 2011, p. 17).

${ }^{3}$ Situada na Mesorregião do Sertão Alagoano, faz parte dos sertões, que são feitos de representações espaciais datadas, construídas historicamente pelo imaginário social e pelas ações dos homens nas quais, inevitavelmente, esse imaginário está incluído. Feito, também, de grafias produzidas pela história dos sujeitos de fora e de dentro dos espaços grafados. Grafias essas "suscetíveis a rasuras e reescritas diversas que revelam o cotidiano dos homens, com suas ambiguidades e contradições, em tempos e espaços específicos, de acordo com as representações selecionadas para o estudo desses espaços." (MELO, A., 2006, p. 85).

${ }^{4}$ A história oral marca os estudos da Educação de Adultos (EDA) e de Jovens e Adultos (EJA) em Alagoas a partir de 2006, no âmbito do Centro de Educação (Cedu), da Universidade Federal de Alagoas (Ufal), quando da realização da pesquisa: A Educação de Jovens e Adultos em Alagoas: incursões na história das políticas ações e concepções no âmbito governamental $(\mathbf{1 9 6 0}$ - 1980). Pesquisa realizada pelo Grupo de Pesquisa CNPq Teorias e Práticas sobre Educação de Jovens e Adultos, sob a coordenação e vice coordenação das pesquisadoras do Cedu/Ufal Tania Moura e Marinaide Freitas.

${ }^{5}$ Concepção da metodologia da História oral do Centro de Pesquisa e Documentação de História Contemporânea do Brasil. Disponível em: http://cpdoc.fgv.br/acervo/historiaoral.

${ }^{6}$ Usamos os termos juntos para garantir a indissociabilidade existente entre eles.

${ }^{7}$ A banda de pífanos é um folguedo do folclore nordestino “[...] também conhecido como 'esquenta-mulher' ou zabumba e, ainda 'carapeba', que é sinônimo de orquestra ou banda desafinada” (FILHO, 1984, p. 79). 